\title{
Cambios en la Cobertura Boscosa en la zona sur de la Montaña de Botaderos, Olancho, utilizando Sensores Remotos y Sistemas de Información Geográfica
}

Yessica Sosa Reyes

\section{Resumen}

El Parque Nacional Montaña de Botaderos se encuentra ubicado en los Departamentos de Olancho, Colón y Yoro, en la zona conocida como su mismo nombre, Montaña de Botaderos, esta zona es de mucho interés, ya que dentro de ella se encuentran especies de flora y fauna de gran importancia para la biodiversidad.

El siguiente artículo muestra los resultados de un período de trece años, una pequeña zona de la parte sur de su zona de amortiguamiento, con aproximadamente $120,043.44 \mathrm{Ha}^{2}$, las Coberturas Boscosas cambian, y para ello se han utilizado imágenes de satélite tipo LANDSAT correspondientes a los años 1998 y 2011, mediante la utilización de programas especializados en el análisis digital y visual de la imagen, los cuales nos ayudan a conocer las diferentes clasificaciones de Coberturas Boscosas utilizando Clasificación no Supervisada y Mixta, añadido a ello un apoyo con programa especializado de sistemas de información geográfica, se elaboraron elaboración mapas en donde muestra los cambios ocurridos en la parte sur de la Zona de Amortiguamiento de la Montaña de Botaderos, en Olancho.

Palabras clave: Zona de Amortiguamiento, Cobertura Boscosa, Imagen Satelital

\section{Abstract}

The Botadero Mountain National Park is located in the departments of Olancho, Colon and Yoro, in the area known as the name, Mountain Dumps, this area is very interesting because within it there are species of flora and fauna of great importance for biodiversity.

The following article shows the results of a thirteen-year period, a small area in the southern part of the buffer zone, approximately 120,043.44 Ha, the forest co- 
ver change, and for that we have used Landsat satellite images corresponding to the type 1998 and 2011, using specialized programs in visual and digital image analysis, which help us to know the different classifications of forest cover using Unsupervised Classification Combination, added to this specialized support systems program geographic information processing where maps showing changes in the southern part of the buffer zone of the Mountain Dumps in Olancho were developed.

Keywords: Buffer Zone, Forest Cover, Satellite Image

Yessica Sosa Reyes, Departamento de Ciencia y Tecnologías de la Información Geográfica - Facultad de Ciencias Espaciales, Universidad Nacional Autónoma de Honduras 


\section{Introducción}

De acuerdo al documento de estudio reciente, sobre la Causas de Deforestación y Degradación de Bosques en Honduras, "históricamente determinadas actividades agrícolas o industriales han incidido directa o indirectamente para fomentar la deforestación o la degradación del bosque aunque las consideraciones para su aprobación en principio hayan sido válidas (desarrollar el país, fomentar actividades productivas, combatir la pobreza rural, etc.). Desde tiempos de La Colonia, extensas áreas forestales fueron sacrificadas para establecer poblados, construcción de casas y edificios públicos, aprovisionarse de leña para uso doméstico y en el procesamiento de minerales y en plantaciones de cacao, causando una temprana deforestación". (Programa de Reducción de Emisiones de la Deforestación y Degradación de Bosques en Centro América y República Dominicana (REDD-CCAD/ GIZ, 2011).

Honduras posee un territorio con una superficie de $112.492 \mathrm{~km} 2$, el 25 por ciento de la cual está cubierta con bosques de pino y el 26 por ciento con bosques Latífoliado. La distribución boscosa en nuestro país hoy en día es de $57 \%$ de Bosque Latífoliado $(3,747,913$, ha.), $38 \%$ de Bosque de Coniferas $(2,579,153$ ha.), $2 \%$ del Bosque Mixto (115,313 ha), $2 \%$ de Bosque de Mangle (130,894 ha) y $1 \%$ de bosque seco (25,017 ha) (ICF, 2011).

Día a día las condiciones de uso de los recursos forestales se ven manchadas por la falta o no aplicación de políticas que ayuden a hacer buen uso y equitativo de los recursos naturales por lo que se pretende en esta investigación analizar el cambio en la Cobertura Boscosa de la parte sur de la zona de amortiguamiento de la Montaña de Botaderos, Olancho.

El uso de las tecnologías hoy en día trae la innovación de hacer en menos tiempo y más precisos los trabajos investigativos y con el fin de hacer demostraciones de un manejo de los Recursos Naturales aplicando Sistemas de Información Geográfica que nos ayude a analizar estos procesos investigativos.

Cambios en la Cobertura Boscosa en la zona sur de la Montaña de Botaderos, Olancho, utilizando...

Los resultados esperados de esta investigación servirán para muchos estudiantes de las carreras de Biología, Forestal, Agronomía y otros que se interesen en el manejo, sostenibilidad y buen uso de los recursos naturales. 
Los resultados esperados serán; Áreas de Cobertura boscosas que presentan un cambio en el período de tiempo de 1998 y 2011 (trece años), cartografía temática de la zona sur del área protegida Montaña de Botaderos, Olancho.

En la actualidad no se ha hecho una concientización sobre la perdida de nuestros recursos naturales, lo que este problema conlleva a malas prácticas de cultivos, en donde estos no son ni los adecuados ni prósperos de un lugar determinado, lo que ayuda a que la inseguridad alimentaria sea cada vez peor.

Existe muchas políticas y leyes que regulan y restringen el manejo adecuado de los bosque en Honduras pero difícilmente estos no son aplicados por diferentes causas y en donde los más desprotegidos son los campesinos que viven en las zonas aledañas al lugar. Con este estudio se pretende dar una pauta que ayude a mejorar no solamente las condiciones de las personas que viven allí sino también la convivencia entre el resto de las especies de flora y fauna que sea manejado de una manera adecuada y sostenible.

\section{Metodología}

Se realizó el análisis de la Cobertura vegetal, mediante la utilización de imágenes de satelital LANDSAT 5 y 7 para el período 1998-2011 realizando el proceso digital de las imágenes y el análisis del cambio en las Coberturas boscosas con el programa ERDAS Imagine y ArcGis para la elaboración de la cartografía Temática. Para la clasificación se utilizó la Clasificación no Supervisada y Mixta, ya que se tiene conocimiento del área por estudios anteriores (Plan de manejo Forestal área Comunitaria EL Boquerón 2010).

\section{Obtención de imágenes satelitales}

Las imágenes satelitales fueron descargadas gratuitamente del servidor de la NASA en la siguiente dirección http://glovis.usgs.gov/, correspondientes a los años 1998 (Figura 1) y 2011 (Figura 2), se muestra una tabla de las características principales de cada una de las imágenes (Tabla 1), también se muestran de la concordancia que existen en cuanto información cartográfica de cada imagen, para no tener variaciones por proyección u otros parámetros (Figuras 3 y 4 ). 


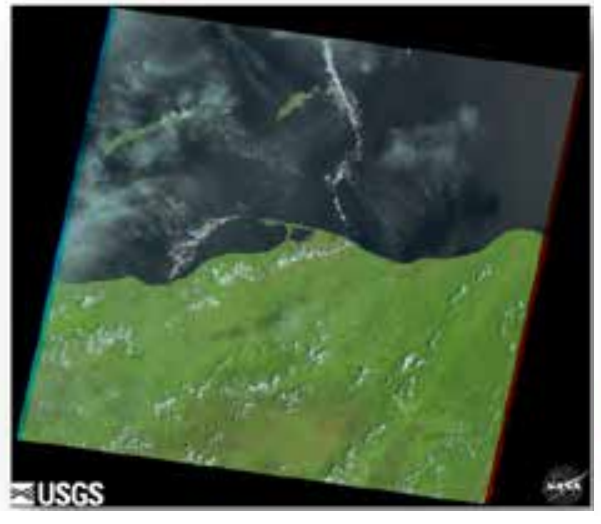

Figura 1. Imagen del Área correspondiente al Año 1998

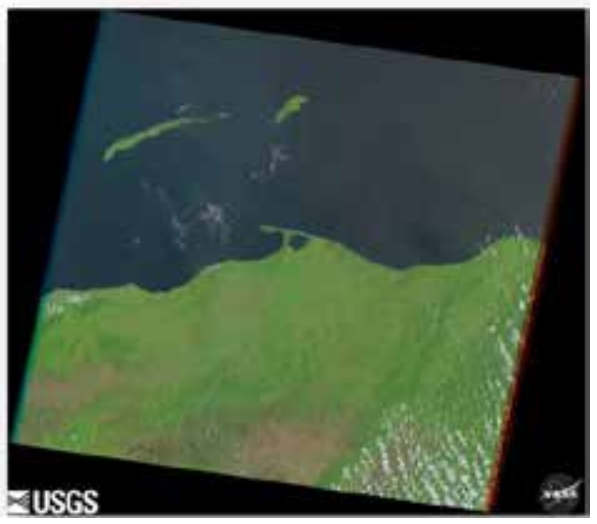

Figura 2. Imagen del Área correspondiente al año 2011

Las características de estas imágenes son las siguientes:

Tabla 1. Características de imágenes

\begin{tabular}{lll}
\hline Descripción & Imagen 1998 & Imagen 2011 \\
\hline Landsat Scene & LT50170491998036XXX01 & LT50170492011024CHM00 \\
Spacecraft & Landsat 5 & LANDSAT 5 \\
Sensor & TM & TM \\
Sensor Mode & SAM & BUMPER \\
Date Adquired & $1998-02-05$ & $2011-01-24$ \\
Sun Azimut & 131.73202164 & 138.73830872 \\
SunElvation & 43.75243737 & 44.09662597 \\
MapProjection & UTM & UTM \\
DATUM & WGS84 & WGS84 \\
Elipsoid & WGS84 & WGS84 \\
UTM Zone & 16 & 16 \\
Orientation & North up & North up \\
Tamaño de la Imagen & $30 \times 30$ metros & $30 \times 30$ metros \\
\hline
\end{tabular}




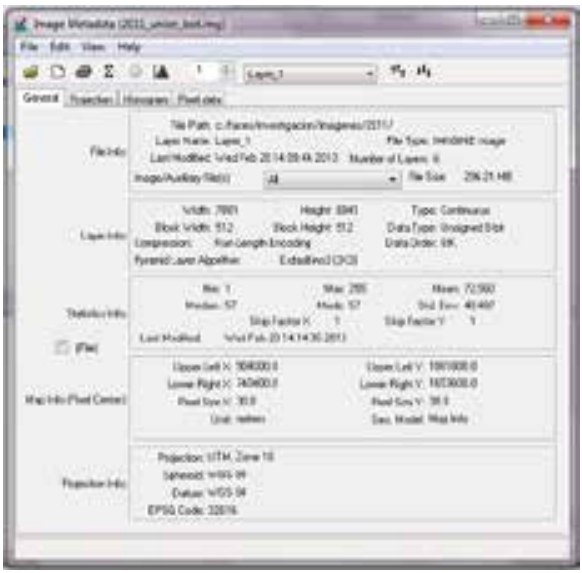

Figura 4. Metadatos Imagen 1998

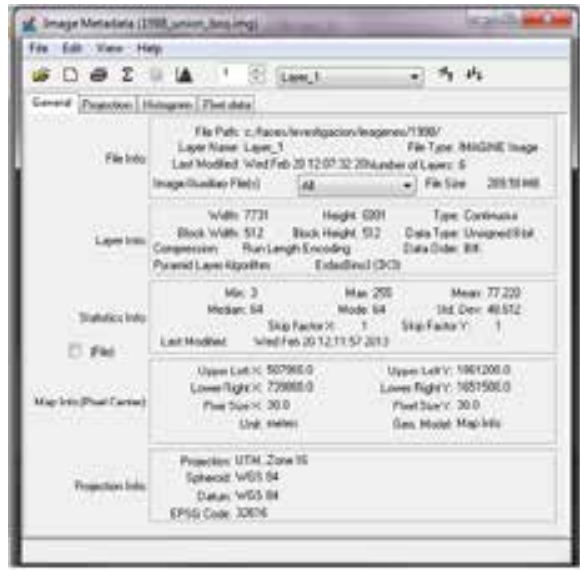

Figura 3. Metadatos de Imagen 2011

\section{Tratamiento digital de imágenes}

Este tratamiento digital de imagen consiste en el tratamiento de una imagen Multiespectral el cual el sensor mide la reflectancia en muchas bandas permitiendo combinar los distintos valores para crear la imagen, esta imágenes pueden estará constituidas entre 3 a 7 bandas, para el tratamiento de las imágenes correspondientes a los años 1998 y 2011 son de 6 bandas (Chuvieco, E. 2002).

Previo a esta etapa de pre procesamiento, se realizó la preparación de cada una de las imágenes seleccionadas, uniendo para ello cada una de las bandas espectrales $1,2,3,4,5$ y 7 para el caso de las imágenes Landsat 5 y 7 , teniendo una imagen de tipo ".img" de capa raster (Figura 5).

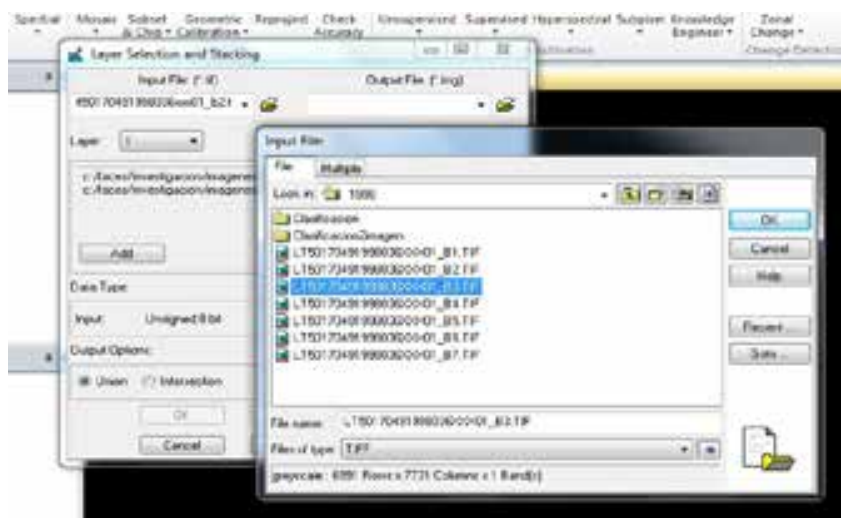

Figura 5. Proceso de Unión de la Imagen 


\section{Corrección Radiométrica de la imagen}

Procedimiento que se realiza para lograr que la imagen convierta los valores de Niveles Digitales a reflectancia, estos valores de niveles digitales se definen desde 0 a 255.

Para ello, mediante un modelo elaborado por el Instituto de Astronomía y Física del Espacio (IAFE) para el cálculo de radiancia, para las imágenes de Landsat se desarrolló el proceso para el cálculo de radiancia con los que se conjugaron los datos obtenidos por la metadato de cada imagen satelital. (Figura 6)

Utilizando el siguiente algoritmo, los valores introducidos para el Modelo del Cálculo de Radiancia son:

DN: Numero DigitaL

\section{$\mathrm{L}-\mathrm{G}^{*} \mathrm{DN}+\mathrm{B}$}

G: Gain

B: Bias

L: Radiancia

cálculo de radiancia - a partir de imagen en contaje

Landasat

Bandas multiespectrales $(1,2,3,4,5,7)$

$L=$ gain $* D N+$ Bias

Imagen de Entrada

OJOI!! REVISAR GAIN Y BIAS DE LANDSAT 5 Y 7

bendes: $1,2,3,4,5,7$

(Costajes)

Pendiente (gain, leer del header)

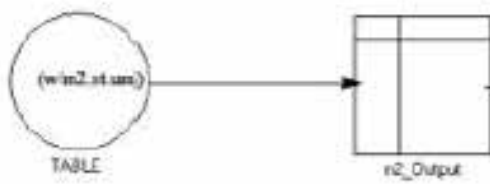

ni. 17.27 or 012 , vike

Bias (offset, leer del beader)

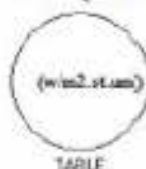

resour

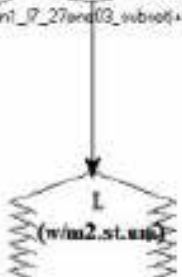

Figura 6. Modelo para Cálculo de Radiancía 


\section{- Clasificación no supervisada}

El cual consiste en definir las clases espectrales presentes en la imagen, de acuerdo a las diferentes combinaciones que se realizaron como ser 321, 432 y 453 para determinar la Cobertura y algunos usos del suelo para definir más claramente el objetivo deseado, mediante el algoritmo de agrupamiento delsodata. Apoyado de esto se contó con trabajo de campo desarrollado para la elaboración del Plan de Manejo de Área Comunitaria El boquerón, ya que este se encuentra dentro de la zona sur de la montaña de botaderos, el cual se podría definir como clasificación mixta. (Figura 7 y 8).

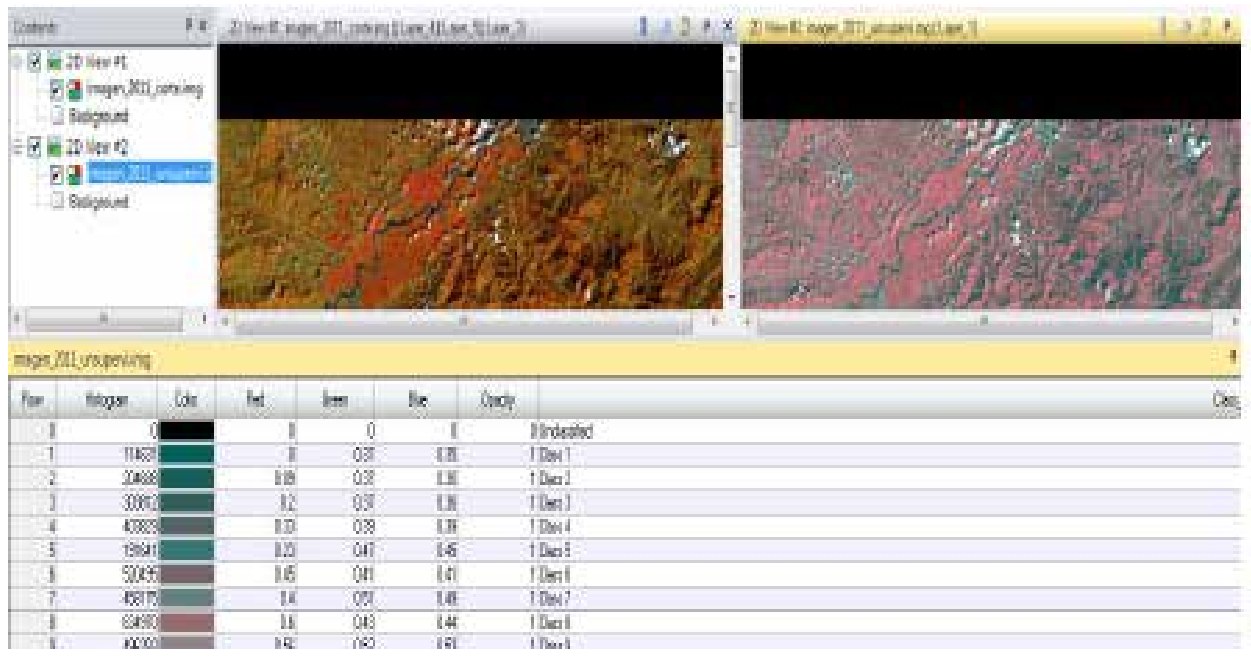

Figura 7. Proceso de Clasificación de Imagen 


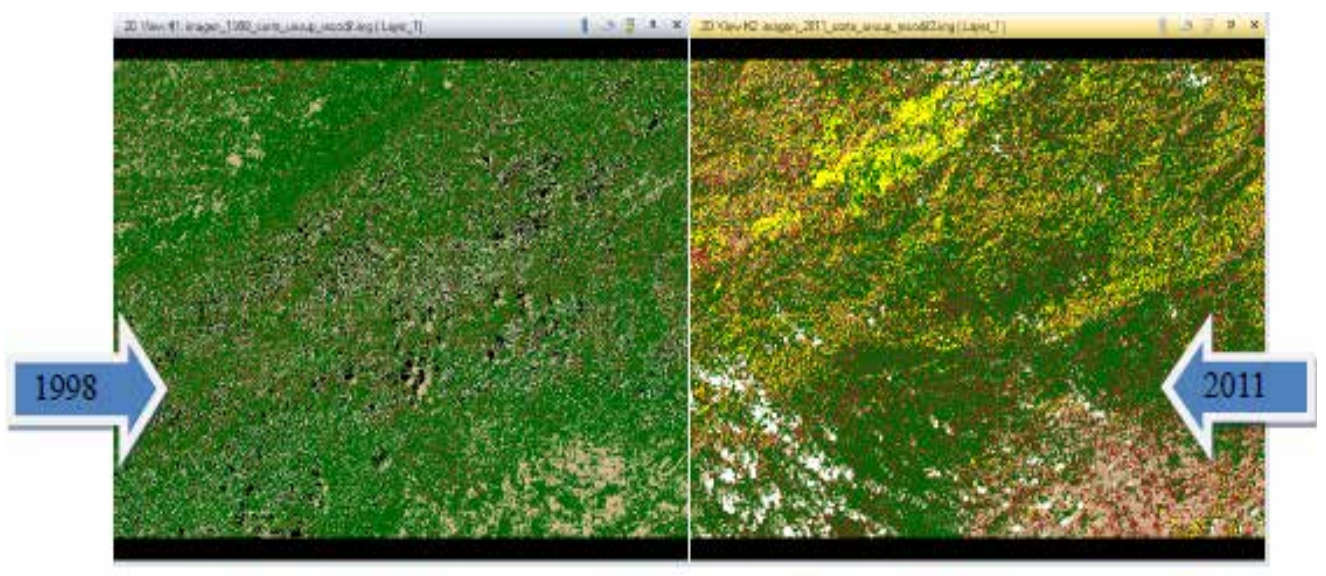

Figura 8. Comparación de imágenes clasificadas de años 1998 y 2011

\section{Resultados}

Como resultado se obtiene que de las dos imágenes y de acuerdo a la clasificación encontrada, se obtengan las siguientes áreas boscosas, ver Tabla 2.

\begin{tabular}{|c|c|c|c|c|}
\hline Clase & $\begin{array}{r}1998 \\
\mathrm{Ha}^{2}\end{array}$ & $\%$ & $\begin{array}{r}2011 \\
\mathrm{Ha}^{2}\end{array}$ & $\%$ \\
\hline Bosque & $B 2,658.11$ & 68.86 & $78,684.94$ & 65.55 \\
\hline Matorral & $12,228.31$ & 10.19 & $14,703.97$ & 12.25 \\
\hline Pasto & $10,137.76$ & 8.45 & $8,183.75$ & 6.82 \\
\hline Agricultura & $15,019.26$ & 12.51 & $18,470.78$ & 15.39 \\
\hline TOTAL & $120,043.44$ & 100 & $120,043.44$ & 100 \\
\hline
\end{tabular}

Tabla 2. Cuadro de áreas resultantes de cada imagen

Como se muestra en el cuadro la Cobertura ha sufrido un cambio considerable, para el caso de la Cobertura boscosa en el período de los años 1998 al 2011, se observa una diferencia de 3,973.17 Ha, y para el caso del matorral aumenta en la zona sur de la zona de amortiguamiento de la montaña de Botaderos, teniendo 
una diferencia de 2,475.66 Ha, causado quizá de las malas prácticas de manejo en la zona, para el caso de la agricultura también a su favor con una diferencia de 3,451.52 Ha, en cambio el Pasto disminuye en su Cobertura teniendo una diferencia de 1,954.01 Ha, estas diferencia hacer concluir que los cambios en la zona se debe a una mala práctica de manejo forestal, ver figuras 9 y 10.

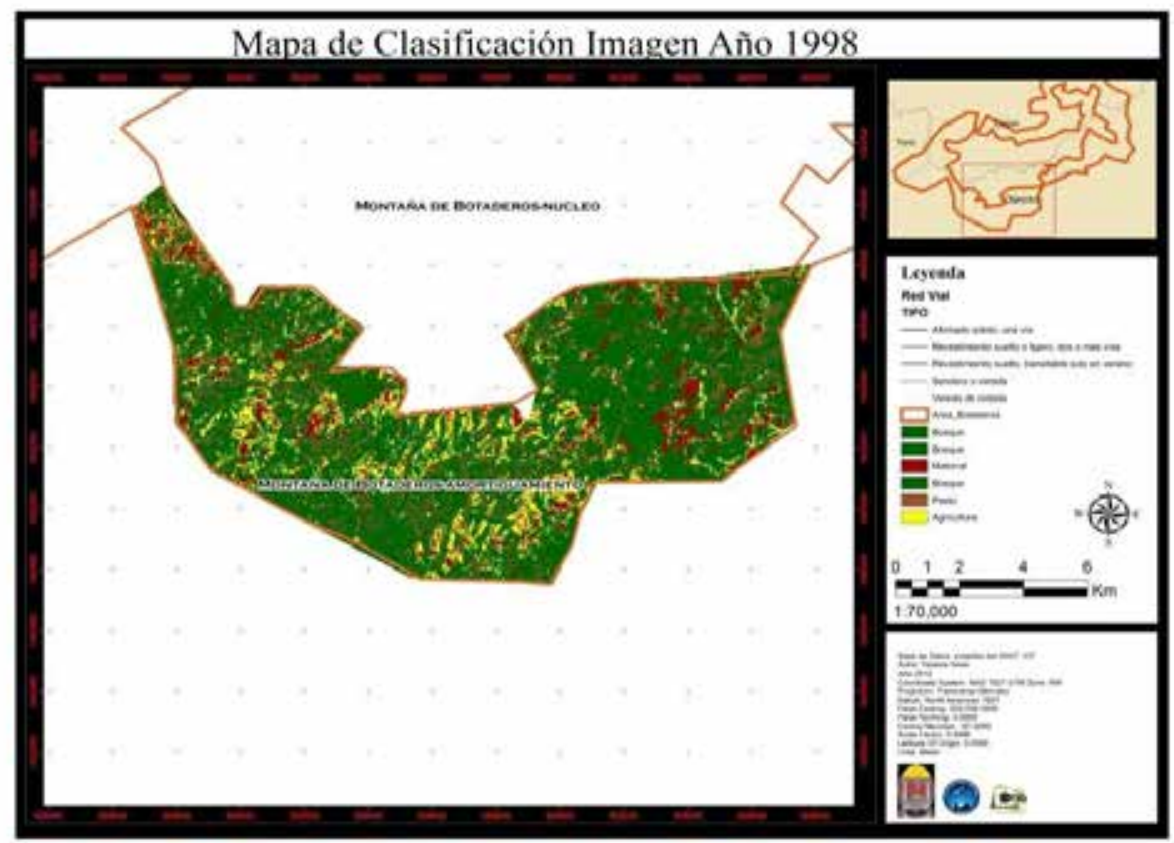

Figura 9. Mapa final con Cobertura Boscosa año 1998 


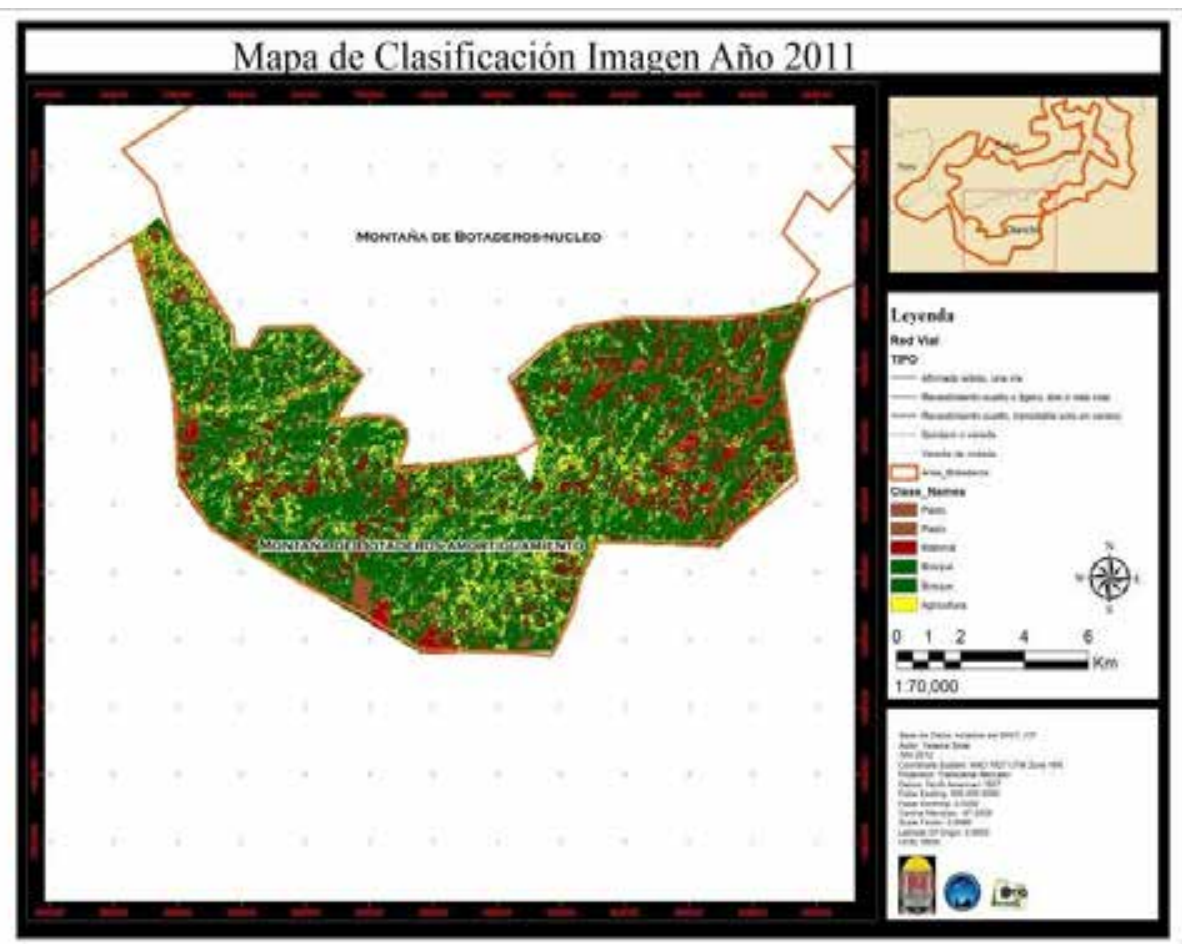

Figura 10. Mapa Final con Cobertura Boscosa año 2011

De acuerdo a lo planteado en la ley forestal, Áreas Protegidas y Vida Silvestre las Zonas Protegidas de los Parques Nacionales debieran ser, ARTíCULO 135.- MEDIDAS DE PROTECCIÓN Y FOMENTO.- Para los fines del Artículo anterior, los propietarios de las Áreas Forestales Públicas y Privadas identificarán áreas deforestadas, degradadas y prioritarias, considerando los requerimientos del desarrollo nacional, incluyendo la generación de empleos.

Las actividades que pueden ser objeto de las medidas de protección y fomento incluyen, las siguientes:

1. Establecimiento de viveros temporales y permanentes;

2. Plantación de árboles energéticos y de uso múltiple, reduciendo la presión sobre los bosques naturales;

3. Plantación de árboles maderables y no maderables; 
4. Defensa y fijación de los suelos forestales y protección de cuencas o zonas protectoras;

5. Apoyo a actividades productivas forestales orientadas a un manejo sostenible de los recursos;

6. Apoyo a las iniciativas de investigación y transferencia de tecnología en el manejo de los Recursos Naturales;

7. Ejecución de actividades silvícola que mejoren la calidad de los bosques;

8. Prevención y protección contra incendios y plagas forestales; y,

9. Quemas prescritas autorizadas por el Instituto Nacional de Conservación y Desarrollo Forestal, Áreas Protegidas y Vida Silvestre (ICF).

\section{Conclusiones}

Las Tecnologías de información Geográfica son una gran herramienta para determinar aspectos de importancia en la toma de decisiones en el Ordenamiento Territorial, el conocer como interactúa una determinada área en un período estimado de cambios puede llegar a ser parte de toma de decisiones en la parte del manejo de los recursos naturales.

Sin embargo es importante que estas investigaciones estén apoyadas de una validación de la zona de estudio en campo, a fin de que, la información analizada ya sea mediante imágenes y fotografías sea lo más real posible.

Es notable la diferencia que se pueda determinar en el análisis de una pequeña parte de esta zona de amortiguamiento, en la zona sur del Parque Nacional, habría que considerar realizar el estudio a más profundidad en la zona para determinar exactamente si las causas de estos cambios son precisamente las de una intervención humana y qué tipo de intervenciones se están realizando en la misma, a fin de afianzar más a las comunidades, municipalidades, entes gobernantes e instituciones internacionales a que estas áreas que están siendo tomadas en cuenta para protegerlas, no solamente se proteja lo que quedó de un mal manejo. (Honduras, 2007). 


\section{Bibliografia}

- Chuvieco, E. (2002). Teledeteccion Ambiental. Barcelona, España: Ariel S.A.

- ICF, I. N. (2011). Anuario Estadistico Forestal. Tegucigalpa, Honduras.

- IAFE, S. d. (2005). Protocolo para el procesamiento de Imagenes Satelitales para Aplicaciones de la Administracion de Parques Nacionales. Buenos Aires, Argentina.

- Cooperación Técnica Alemana-PRORENA-ICF. (2010). Plan de Manejo. Gualaco, Olancho.

- REDD-CCAD/GIZ, (2011).Programa de Reducción de Emisiones de la Deforestación y Degradación de Bosques en Centro América y Republica Dominicana ().Evaluación Preliminar sobre Causas de Deforestación y Degradación de Bosques en Honduras. Tegucigalpa, MDC 